\title{
A Novel Noninvasive Method for Predicting Liver Fibrosis by Quantifying the Estrangement of Indocyanine Green Retention Rate and Tc-99m-diethylenetriamine-penta-acetic Acid-galactosyl Human Serum Albumin Scintigraphy
}

\author{
TAKEHIKO HANAKI, EI UCHINAKA, TAKUKI YAGYU, MASAKI MORIMOTO, JOJI WATANABE, \\ KOZO MIYATANI, KYOICHI KIHARA, TOMOYUKI MATSUNAGA, MANABU YAMAMOTO, \\ YOJI FUKUMOTO, NARUO TOKUYASU, SHUICHI TAKANO, TERUHISA SAKAMOTO, \\ SOICHIRO HONJO, TOSHIMICHI HASEGAWA and YOSHIYUKI FUJIWARA \\ Division of Surgical Oncology, Department of Surgery, School of Medicine, \\ Tottori University Faculty of Medicine, Yonago, Japan
}

\begin{abstract}
Background/Aim: Indocyanine green (ICG) clearance test is one of the most popular dynamic methods for evaluating preoperative liver function to avoid posthepatectomy liver failure (PHLF). Tc-99m-diethylenetriamine-penta-acetic acid-galactosyl human serum albumin scintigraphy (GSA) also facilitates the direct estimation of functional hepatocytes and can estimate the ICG retention rate (R15); however, in some cases, there is a discrepancy between results of a preoperative examination of ICG-R15 and the estimated ICG-R15 obtained by $99 m T c-G S A$ (GSA-R15). This study evaluated the gap between ICG-R15 and GSA-R15 (AICG) for predicting background liver fibrosis in patients who underwent hepatectomy. Patients and Methods: Sixty-four consecutive patients who underwent hepatectomy and preoperative ICG-R15 and GSA-R15 examinations from 2016 to 2019 were retrospectively evaluated. The gap between GSA-RI5 and ICGR15 was defined as $\triangle I C G$ and the factors predicting liver fibrosis were investigated. Results: In the pathologically-proven cirrhotic group, platelet counts were significantly lower and $\triangle I C G$ values were significantly larger than those in the nonlearly-cirrhotic group. A multivariate analysis identified a higher total bilirubin level, a higher AST level, and a larger $\triangle I C G$ level
\end{abstract}

This article is freely accessible online.

Correspondence to: Takehiko Hanaki, MD, Ph.D. (ORCiD ID: 0000-0002-4008-0207), Division of Surgical Oncology, Department of Surgery, School of Medicine, Tottori University Faculty of Medicine, 36-1 Nishi-cho, Yonago, Tottori 683-8503, Japan. Tel: +81 859386567, Fax: +81 859386569, e-mail: hanaki-ttr@umin.ac.jp

Key Words: Tc-99m-diethylenetriamine-penta-acetic acid-galactosyl human serum albumin (GSA) scintigraphy, indocyanine green (ICG), liver function test, liver fibrosis. as significant predictive factors for liver cirrhosis. Conclusion: Larger $\triangle I C G$ was found to be an independent preoperative predictor of liver fibrosis and may positively contribute to decision-making before hepatectomy to avoid PHLF.

Hepatectomy is one of the cornerstone interventions for primary liver cancer to date and is widely performed all over the world $(1,2)$. Long-term improvements in surgical techniques and advances in perioperative management have made surgical treatment safer than ever before $(3,4)$; however, posthepatectomy liver failure (PHLF) remains a serious complication and can lead to a fatal clinical course, with a reported global prevalence of PHLF existing in the realm of $0.7 \%$ to $9.1 \%(1,5)$. To improve the surgical outcomes, it is important to predict accurate liver function based on patients' preoperative assessment. In cases of severe liver dysfunction with liver fibrosis, performing extensive hepatectomy leads to PHLF, so predicting patients with severe background liver changes facilitates the consideration of alternative interventions to prevent or reduce the chances of PHLF $(6,7)$.

In addition to various liver function tests, indocyanine green (ICG) tests are generally performed to evaluate how safe hepatectomy can be performed, and ICG test results are adopted, for example, as criteria for the degree of liver damage. The ICG test was introduced by Makuuchi et al. and popularized in the $1980 \mathrm{~s}$, especially in patients with hepatocellular carcinoma (HCC) $(1,8)$. On the other hand, the ICG test, like other tests, cannot stand alone for all liver function evaluations. It is known that, in patients with intrahepatic shunt, ICG excretion disorder, and jaundice liver, the ICG test does not always accurately reflect liver function $(9,10)$. In fact, even if the preoperative ICG-R15 score is normal, this finding may be a result of the finding that progression of liver fibrosis at the time of laparotomy is 
sometimes experienced. Efforts to accurately evaluate liver function should be continued in the future, while, in our facility, Tc-99m-diethylenetriamine-penta-acetic acidgalactosyl human serum albumin scintigraphy (GSA) is used as a more accurate index for the evaluation of preoperative liver function $(9,11,12)$. There are various models for liver function evaluation by GSA, but liver receptor index (LHL15, uptake ratio of the liver to the liver plus heart at $15 \mathrm{~min}$ ) and clearance index (HH15, uptake ratio of the heart at 15 min to that at three min) are the most commonly used parameters of GSA. These indices are known to be useful in the evaluation of reserve liver capacity $(11,13,14)$. A method to calculate the estimated ICG-R15 by GSA (GSA-R15) and replace it preoperatively with the ICG retention rate (ICG-R15) has also been reported (9). Ideally, the scores of ICG-R15 and GSAR15 should match; however, at some instances we experience disparities between the two scores, especially in case of liver cirrhosis. Therefore, this retrospective study focused on the gap of GSA-R15 and ICG-R15 as preoperative evaluations of liver function and aimed to investigate whether this difference can be a factor for the prediction of liver fibrosis prior to liver resection.

\section{Patients and Methods}

Patients and surgical procedures. The study cohort consisted of 64 consecutive patients who underwent elective hepatectomy with the preoperative diagnosis of primary hepatic cancer and a preoperative evaluation involving GSA and ICG tests at Tottori University Hospital from April 2016 to March 2019. Patients' clinicopathological data were collected from electric medical records retrospectively. Indications for hepatectomy included the following factors: Eastern Cooperative Oncology Group performance status of grade 2 or higher, preserved estimated remnant liver function from ICG test, GSA and volumetric computed tomography, and stable general condition without serious organ dysfunction. Either anatomical resection or nonanatomical resection was selected based on the patient's liver function and remnant liver volume. Anatomic resection was defined as at least one Couinaud's subsegment removal containing the tumor.

ICG clearance test. Prior to liver resection, $0.5 \mathrm{mg} / \mathrm{kg}$ of ICG (Daiichi Sankyo Company, Ltd., Tokyo, Japan) was injected into a peripheral vein of the patient. Accordingly, at five, 10, or $15 \mathrm{~min}$, blood samples were collected and the clearance rate (ICG-K) and 15-min ICG-R15 were calculated using a spectrophotometer (Diango meter; Mituwa Frontech Corp., Osaka, Japan).

Blood tests. The data of 13 blood indices [i.e., albumin, total protein, total bilirubin, aspartate transaminase (AST), alanine aminotransferase (ALT), white blood cell/neutrophil/lymphocyte/ platelet count (WBC/Neu/Lym/PLT), prothrombin time activity (PT), C-reactive protein (CRP), $\alpha$-fetoprotein (AFP) and protein induced by vitamin $\mathrm{K}$ absence II (PIVKA-II)] were collected at least within one week prior to the hepatectomy. Fibrosis-4 index (FIB-4) was calculated as described previously $(15,16)$, and used as an established and well known preoperative fibrosis marker.
Table I. Patient characteristics.

\begin{tabular}{|c|c|}
\hline Characteristics & All patients $(n=64)$ \\
\hline Age (years) & $70(40-90)$ \\
\hline Gender $(\mathrm{M} / \mathrm{F})$ & $53 / 11$ \\
\hline BMI $\left(\mathrm{kg} / \mathrm{m}^{2}\right)$ & $23(17.7-30.0)$ \\
\hline \multicolumn{2}{|l|}{ Etiology } \\
\hline $\mathrm{HBV} / \mathrm{HCV} /$ non-B, non-C & $33 / 4 / 27$ \\
\hline ASA-PS(1/2/3/4) & $1 / 55 / 8 / 0$ \\
\hline ECOG-PS(0/1/2/3/4) & $53 / 11 / 0 / 0 / 0$ \\
\hline Albumin $(\mathrm{g} / \mathrm{dl})$ & $4.3(3.2-4.9)$ \\
\hline Total protein $(\mathrm{g} / \mathrm{dl})$ & $7.15(6.0-8.4)$ \\
\hline Total bilirubin (mg/dl) & $0.7(0.3-1.6)$ \\
\hline AST (U/l) & $25(9-66)$ \\
\hline $\operatorname{ALT}(\mathrm{U} / 1)$ & $25(10-77)$ \\
\hline $\mathrm{CRP}(\mathrm{mg} / \mathrm{dl})$ & $0.1(0.01-15)$ \\
\hline \multicolumn{2}{|l|}{ Complete blood count } \\
\hline $\mathrm{WBC}(/ \mu \mathrm{l})$ & $5250(2,700-10,100)$ \\
\hline PLT $\left(\times 10^{4} / \mu \mathrm{l}\right)$ & $17.7(7.6-45.7)$ \\
\hline Neutrophil $(/ \mu \mathrm{l})$ & $3,246(1,350-7,878)$ \\
\hline Lymphocyte $(/ \mu \mathrm{l})$ & $1,377(371-2,970)$ \\
\hline PT $(\%)$ & $92.3(28-118.9)$ \\
\hline Child-Pugh score $(5 / 6 / 7 />7)$ & $56 / 7 / 1 / 0$ \\
\hline Child-Pugh grade $(\mathrm{A} / \mathrm{B} / \mathrm{C})$ & $63 / 1 / 0$ \\
\hline Liver damage $(\mathrm{A} / \mathrm{B} / \mathrm{C})$ & $60 / 4 / 0$ \\
\hline $\operatorname{AFP}(\mathrm{ng} / \mathrm{ml})$ & $3.4(0.9-15139)$ \\
\hline PIVKA-II (mAU/ml) & $96(15-87,700)$ \\
\hline FIB-4 index & $2.0(0.6-5.7)$ \\
\hline ICG-R15 (\%) & $13(4-30)$ \\
\hline ICG-K & $0.14(0.08-0.22)$ \\
\hline HH15 & $0.59(0.41-0.71)$ \\
\hline LHL15 & $0.92(0.84-0.97)$ \\
\hline $\begin{array}{l}\text { Estimated ICG-R15 from 99mTc-GSA } \\
\text { (GSA-R15, \%) }\end{array}$ & $14.2(9.8-27.1)$ \\
\hline$\triangle \mathrm{ICG}$ & $2.0(-18.2$ to 11.7$)$ \\
\hline Operative procedure (Open/laparoscopic) & $52 / 12$ \\
\hline $\operatorname{Hr}(0+\mathrm{S} / 1 / 2 / 3)$ & $17 / 35 / 12 / 0$ \\
\hline Operation time (min) & $468(163-913)$ \\
\hline Intraoperative bleed (ml) & $477.5(10-1,940)$ \\
\hline In-hospital mortality (\%) & 0 \\
\hline $\mathrm{F} 0 / 1 / 2 / 3 / 4$ & $18 / 16 / 8 / 12 / 10$ \\
\hline Histological diagnosis (HCC/CCC/others) & $51 / 6 / 7$ \\
\hline
\end{tabular}

Calculation of GSA-R15. 99mTc-GSA was supplied by Nihon MediPhysics (Tokyo, Japan). After intravenous injection of 185 MBq99mTc-GSA, dynamic imaging was performed with the supine position, using a gamma camera and single photon-emission computed tomography (Symbia Intevo 6; Siemens AG, Munich, Germany). The region of interest (ROI) was defined for the liver and heart using standard imaging software. LHL15 and HH15 were calculated as described previously (9). Shortly, LHL15 was calculated by dividing the radioactivity of the ROI of the liver by the radioactivity of the ROI of the liver and the heart at 15 min after injection. HH15 was calculated by dividing the radioactivity of the ROI of the heart $15 \mathrm{~min}$ after injection by that $3 \mathrm{~min}$ after injection. GSA-R15 was calculated using the formula reported by Kawamura et al. (17). In patients with liver damage A, the conversion formula GSA-R15=114-108*LHL15 was used, while, in the patients with 


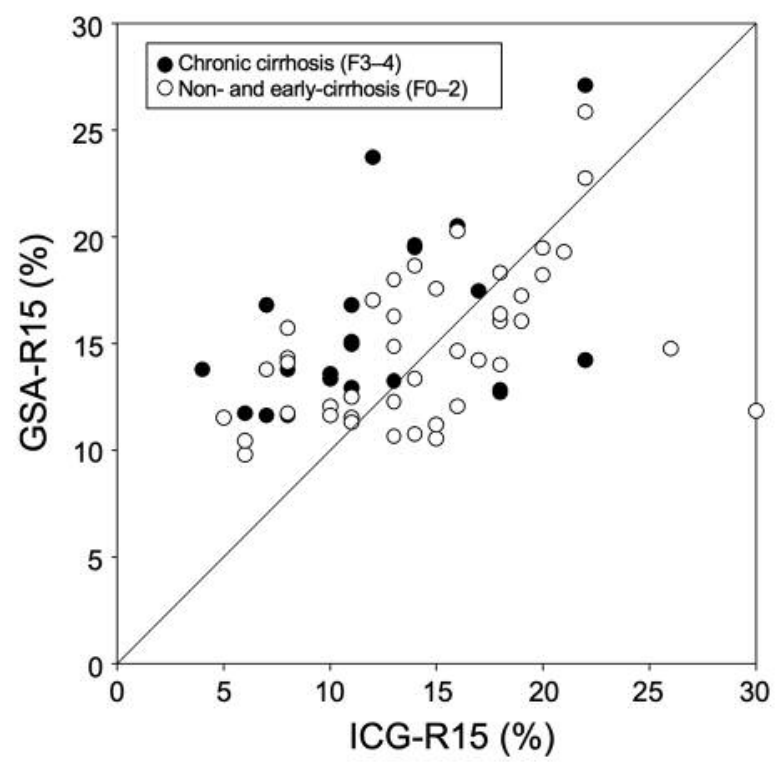

Figure 1. Correlation between ICG-R15 and GSA-R15. There is a strong positive correlation between the two indices $(r=0.739$, Pearson correlation coefficient); however, there is also some variation. The group with higher GSA-R15 than ICG-R15 included a higher proportion of patients with advanced fibrosis (F3-4).

liver damage B, the conversion formula GSA-R15=-41+103*HH15 was used. Estrangement of GSA-R15 and ICG-R15 was defined as " $\triangle \mathrm{ICG}$ " using the following formula: $\triangle \mathrm{ICG}=\mathrm{GSA}-\mathrm{R} 15-\mathrm{ICG}-\mathrm{R} 15$.

Liver specimens. Human liver specimens were obtained during surgery as described above. Formalin-fixed, paraffin-embedded liver specimens were cut into sections. After hematoxylin and eosin staining, and Mallory-Azan or Elastica van Gieson staining, the samples were microscopically examined. Based on the Inuyama classification (18), the degree of liver fibrosis was assessed and the patients were divided into two groups: a non- and early-cirrhotic $(\mathrm{F} 0+\mathrm{F} 1+\mathrm{F} 2)$ group and a chronic cirrhosis $(\mathrm{F} 3+\mathrm{F} 4)$ group.

Statistical analysis. IBM SPSS Statistics for Macintosh, version 25.0 (IBM Corp., Armonk, NY, USA) and GraphPad Prism 6 (GraphPad Software, Inc., La Jolla, CA, USA) were used for all graph drawings and statistical analyses. Continuous data are presented as medians with ranges. The Mann-Whitney $U$-test and chi-squared test were used to analyse the significance of associations. Regression analyses were conducted to identify preoperative factors related to $\triangle \mathrm{ICG}$. Uniand multivariate logistic regression analyses were applied to determine the preoperative factors affecting liver cirrhosis (F3-F4). The predictive values for liver cirrhosis (F3-F4) were evaluated by a receiver operating characteristic (ROC) analysis. The area under the curve (AUC) was computed using the nonparametric trapezoidal method (19) and 95\% confidence intervals (CIs) were obtained using the approach described by DeLong et al. (20). p-Values were twosided and considered significant if less than 0.05 .

Ethics. All procedures in this study were performed in accordance with the ethics standards of the study institution and with the 1964
Declaration of Helsinki. The Ethics Committee of the Graduate School of Medicine, Tottori University approved this study (approval no. 17A135). For this type of study, formal patient consent was not required.

\section{Results}

Patients characteristics. Patient characteristics are summarized in Table I. Overall, 64 patients (53 men and 11 women) underwent hepatectomy with a preoperative diagnosis of primary liver cancer who were postoperatively diagnosed with HCC $(n=51)$, cholangiocellular carcinoma (CCC; $n=6)$, or other condition (including combined HCC and CCC and other neoplasms; $n=7)$. The median age of the included patients was 70 years (range $=40-90$ years). F0, no fibrosis $(n=18)$; F1, expansion of the portal tracts without linkage $(n=16) ; F 2$, portal expansion with portal to portal linkage $(n=8) ; F 3$, extensive portal to portal and focal portal to central linkage $(n=12)$; and $\mathrm{F} 4$, cirrhosis $(\mathrm{n}=10)$. The causes of liver diseases were hepatitis $\mathrm{B}$ in 33 patients $(51.6 \%)$, hepatitis $\mathrm{C}$ in four patients $(6.3 \%)$, and non-B/non-C in 27 patients (41.2\%). The median ICG-R15 and GSA-R15 values were approximately $13.0 \%$ (range $=4$ $30 \%$ ) and $14.2 \%$ (range $=9.8-27.1 \%$ ), respectively. The ChildPugh scores ranged from five to seven points. There were no patients who underwent hepatectomy with Child-Pugh grade $\mathrm{C}$ and/or liver damage grade $\mathrm{C}$. The median AFP and PIVKA-II results were $3.4 \mathrm{ng} / \mathrm{ml}$ (range $=0.9-15,139 \mathrm{ng} / \mathrm{ml}$ ) and 96 $\mathrm{mAU} / \mathrm{ml}$ (range $=15-87,700 \mathrm{mAU} / \mathrm{ml})$, respectively, at the time of liver resection. The majority of patients $(73.4 \%)$ underwent anatomical resection. The median operation time was $468 \mathrm{~min}$ (range $=163-913 \mathrm{~min}$ ) and the median blood loss volume was $478 \mathrm{ml}$ (range=10-1940 $\mathrm{ml}$ ). There was no in-hospital mortality. After plotting the scores (ICG-R15 and GSA-R15) on a scatterplot, it seemed that there were some disparities between the two indices (Figure 1). We found that there was a dissociation in two indices. Furthermore, in patients showing larger GSA-R15 than ICG-R15 outcomes, histopathological evaluation after surgery often resulted in fibrosis in the background liver.

Preoperative predictive factors for liver fibrosis. The comparison of the $\triangle \mathrm{ICG}$ values was done between patients in the non-/early-cirrhotic group (F0-2) and patients in the chronic cirrhosis group (F3-4) as shown in Figure 2. $\triangle \mathrm{ICG}$ was significantly larger in patients with chronic cirrhosis $(p=0.012)$. The diagnostic accuracy of $\triangle \mathrm{ICG}, \mathrm{ICG}-\mathrm{R} 15$, and GSA-R15 regarding the occurrence of chronic cirrhosis (F3-4) was evaluated by the AUCs as shown in Figure 3. In comparing the three factors, the $\triangle \mathrm{ICG}$ presented the highest diagnostic accuracy ( $\mathrm{AUC}=0.692 ; 95 \% \mathrm{CI}=0.58$ $0.84)$. The optimal cutoff value was calculated as 3.4 by maximizing Youden's index (21). Using the cutoff value, the sensitivity and specificity of $\triangle \mathrm{ICG}$ for chronic cirrhosis (F3-4) were $0.727 \quad(95 \% \mathrm{CI}=0.55-0.91)$ and 0.690 


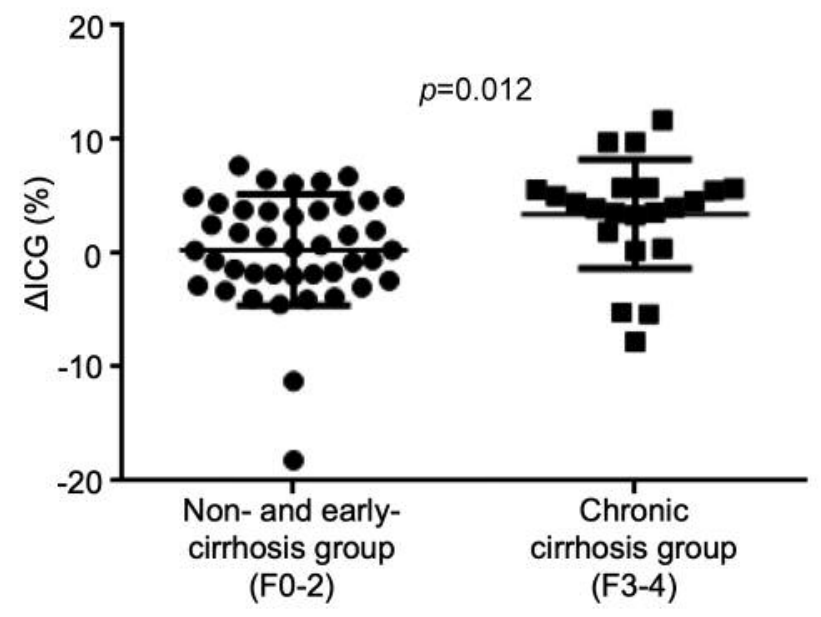

Figure 2. Comparison of $\triangle I C G$ between two groups: patients with nonlearly- cirrhosis and chronic cirrhosis (Mann-Whitney U-test).

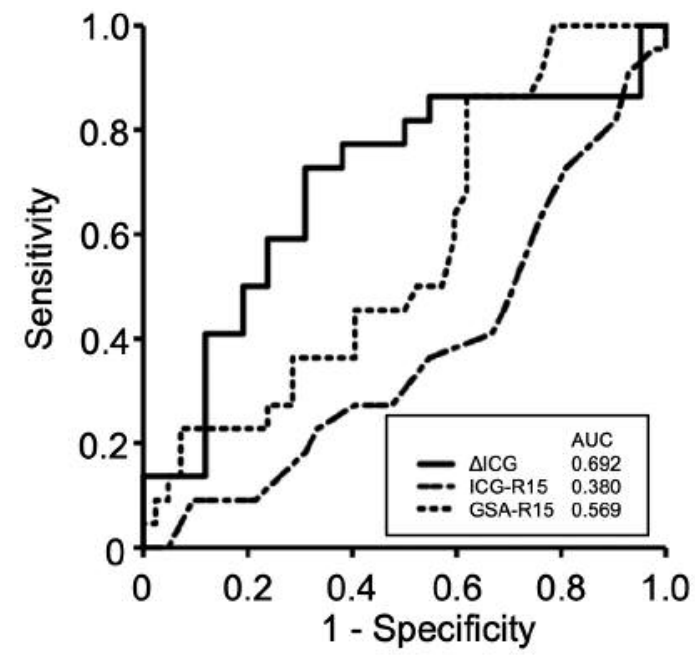

Figure 3. ROCs for the diagnostic accuracy of $\triangle I C G, I C G-R 15$, and GSA-R15 in predicting chronic cirrhosis (F3-4). AUC: Area under the receiver operating characteristic curve.

Table II. Univariate and multivariate analysis: predictive factors for larger $\triangle I C G$ (>3.4).

\begin{tabular}{|c|c|c|c|c|c|c|}
\hline \multirow[t]{2}{*}{ Characteristics } & \multicolumn{3}{|c|}{ Univariate analysis } & \multicolumn{3}{|c|}{ Multivariate analysis } \\
\hline & Odds ratio & $(95 \% \mathrm{CI})$ & $p$-Value & Odds ratio & $(95 \% \mathrm{CI})$ & $p$-Value \\
\hline Age (year) & 0.964 & $(0.920-1.011)$ & 0.136 & & & \\
\hline Gender (Male) & 1.174 & $(0.318-4.337)$ & 0.810 & & & \\
\hline BMI $\left(\mathrm{kg} / \mathrm{m}^{2}\right)$ & 0.813 & $(0.672-0.983)$ & 0.033 & 0.912 & $(0.716-1.163)$ & 0.459 \\
\hline Albumin $(\mathrm{g} / \mathrm{dl})$ & 0.854 & $(0.251-2.908)$ & 0.800 & & & \\
\hline Total protein $(\mathrm{g} / \mathrm{dl})$ & 0.681 & $(0.220-2.113)$ & 0.506 & & & \\
\hline Total bilirubin $(\mathrm{mg} / \mathrm{dl})$ & 1.528 & $(0.262-8.900)$ & 0.637 & & & \\
\hline AST (U/l) & 1.058 & $(1.005-1.114)$ & 0.031 & 1.013 & $(0.931-1.102)$ & 0.767 \\
\hline $\operatorname{ALT}(\mathrm{U} / \mathrm{l})$ & 0.992 & $(0.960-1.025)$ & 0.645 & & & \\
\hline $\mathrm{CRP}(\mathrm{mg} / \mathrm{dl})$ & 0.820 & $(0.559-1.204)$ & 0.311 & & & \\
\hline \multicolumn{7}{|l|}{ Complete Blood Count } \\
\hline WBC $(/ \mu \mathrm{l})$ & 1.000 & $(0.999-1.0004)$ & 0.751 & & & \\
\hline PLT $\left(\times 10^{4} / \mu \mathrm{l}\right)$ & 0.989 & $(0.955-1.025)$ & 0.553 & & & \\
\hline Neutrophil $(/ \mu \mathrm{l})$ & 1.000 & $(0.999-1.0004)$ & 0.972 & & & \\
\hline Lymphocyte $(/ \mu \mathrm{l})$ & 1.000 & $0.999-1.002)$ & 0.343 & & & \\
\hline PT $(\%)$ & 1.005 & $(0.977-1.034)$ & 0.733 & & & \\
\hline FIB 4 index & 8.339 & $(2.218-31.35)$ & 0.002 & 8.436 & $(1.928-36.9)$ & 0.005 \\
\hline $\operatorname{AFP}(n g / m l)$ & 1.000 & $(0.999-1.0002)$ & 0.665 & & & \\
\hline PIVKA-II (mAU/ml) & 1.000 & $(0.999-1.0004)$ & 0.441 & & & \\
\hline
\end{tabular}

(95\% CI $=0.55-0.83)$, respectively. In addition, the cutoff value of 3.4 for $\triangle \mathrm{ICG}$ yielded a positive predictive value of $0.556(95 \% \mathrm{CI}=0.371-0.740)$ and a negative predictive value of $0.811(95 \% \mathrm{CI}=0.683-0.939)$. In order to examine the clinical factors predicting larger $\triangle \mathrm{ICG}$ values $(\geq 3.4)$, we performed a logistic analysis. The FIB-4 was included into this analysis because it is a well-established noninvasive test for predicting liver fibrosis $(16,22)$. Other preoperative factors chosen for the analysis were as follows: age, sex, body mass index (BMI), albumin, total bilirubin, AST, ALT, CRP, WBC, PLT, Neu, Lym, PT, AFP, and PIVKA-II. The univariate and multivariate analyses revealed only larger FIB-4 index values to be significantly and independently associated with larger $\triangle \mathrm{ICG}(>3.4)$ $(p=0.005)$ (Table II).

$\triangle I C G$ as a liver fibrosis predictor. Table III demonstrates the comparisons of clinicopathological parameters according to 
Table III. Comparison of patient characteristics according to grades of cirrhosis.

\begin{tabular}{|c|c|c|c|}
\hline Characteristics & F0-2 $(n=42)$ & $F 3-4(n=22)$ & $p$-Value \\
\hline Age (year) & $72.5[47-90]$ & $66.5[40-87]$ & 0.101 \\
\hline Gender $(\mathrm{M} / \mathrm{F})$ & $34 / 8$ & $19 / 3$ & 0.586 \\
\hline BMI $\left(\mathrm{kg} / \mathrm{m}^{2}\right)$ & $22.9[17.4-30.0]$ & $23.2[18.0-28.8]$ & 0.876 \\
\hline \multicolumn{4}{|l|}{ Etiology } \\
\hline $\begin{array}{l}\mathrm{HBV} / \mathrm{HCV} / \text { Non B, } \\
\text { Non C }\end{array}$ & $19 / 2 / 21$ & $14 / 2 / 6$ & 0.207 \\
\hline ASA-PS (1/2/3/4) & $1 / 37 / 4 / 0$ & $0 / 18 / 4 / 0$ & 0.483 \\
\hline ECOG-PS $(0 / 1 / 2 / 3 / 4)$ & $34 / 8 / 0 / 0 / 0$ & $19 / 3 / 0 / 0 / 0$ & 0.59 \\
\hline Albumin (g/dl) & $4.2[3.2-4.9]$ & $4.3[3.2-4.8]$ & 0.966 \\
\hline Total protein $(\mathrm{g} / \mathrm{dl})$ & $7.2[6.2-8.4]$ & $7.1[6.0-8.3]$ & 0.474 \\
\hline Total bilirubin $(\mathrm{mg} / \mathrm{dl})$ & $0.6[0.3-1.3]$ & $0.8[0.4-1.6]$ & 0.040 \\
\hline $\operatorname{AST}(\mathrm{U} / 1)$ & $24.5[9-50]$ & $31[19-66]$ & 0.002 \\
\hline $\operatorname{ALT}(\mathrm{U} / \mathrm{l})$ & $25[10-77]$ & $24.5[58]$ & 0.983 \\
\hline $\mathrm{CRP}(\mathrm{mg} / \mathrm{dl})$ & $0.14[0.01-15]$ & $0.09[0.02-1.38]$ & 0.115 \\
\hline \multicolumn{4}{|l|}{$\mathrm{CBC}$} \\
\hline $\mathrm{WBC}(/ \mu \mathrm{l})$ & $5,200[3,100-10,100]$ & $5,300[3,800-10,000]$ & 0.977 \\
\hline PLT $\left(\times 10^{4} / \mu \mathrm{l}\right)$ & $18.3[7.6-34.0]$ & $14.9[8.6-45.7]$ & 0.016 \\
\hline Neutrophil $(/ \mu \mathrm{l})$ & 3,306 [1798-7878] & $3,510[1,833-7,500]$ & 0.854 \\
\hline Lymphocyte $(/ \mu \mathrm{l})$ & $1,220[899-2695]$ & $1,440[371-2,970]$ & 0.412 \\
\hline PT $(\%)$ & $95.5[28.0-118.9]$ & 87.1 [71.2-106.9] & 0.213 \\
\hline $\begin{array}{l}\text { Child Pugh score } \\
(5 / 6 / 7 />7)\end{array}$ & $35 / 7 / 0 / 0$ & $21 / 0 / 1 / 0$ & 0.055 \\
\hline $\begin{array}{l}\text { Child Pugh grade } \\
\text { (A/B/C) }\end{array}$ & $42 / 0 / 0$ & $21 / 1 / 0$ & 0.164 \\
\hline $\begin{array}{l}\text { Liver damage } \\
(\mathrm{A} / \mathrm{B} / \mathrm{C})\end{array}$ & $40 / 2 / 0$ & $20 / 2 / 0$ & 0.497 \\
\hline AFP (ng/ml) & $3.1[1.0-9,290]$ & $5.0[1.0-15,139]$ & 0.987 \\
\hline PIVKA-II (mAU/ml) & $78[16-87,700]$ & $84[15-22,551]$ & 0.833 \\
\hline FIB 4 inex & $1.8[0.599-2.99]$ & $2.5[1.50-5.74]$ & $<0.001$ \\
\hline ICG-R15 (\%) & $15[5-30]$ & $11[4-22]$ & 0.116 \\
\hline ICG-K & $0.14[0.08-0.22]$ & $0.15[0.10-0.20]$ & 0.056 \\
\hline HH15 & $0.58[0.41-0.71]$ & $0.60[0.51-0.71]$ & 0.140 \\
\hline LHL15 & $0.93[0.84-0.97]$ & $0.92[0.84-0.95]$ & 0.631 \\
\hline $\begin{array}{l}\text { Estimated ICG-R15 } \\
\text { from } 99 \mathrm{mTc}-\mathrm{GSA} \\
(\mathrm{GSA}-\mathrm{R} 15, \%)\end{array}$ & $14.1[9.8-25.8]$ & $14.2[11.6-27.1]$ & 0.369 \\
\hline$\triangle \mathrm{ICG}$ & $0.51[-18.2$ to 7.7$]$ & $4.1[-7.8$ to 11.7$]$ & 0.012 \\
\hline $\begin{array}{l}\text { Operative procedure } \\
\text { (Open/Laparoscopic) }\end{array}$ & $32 / 10$ & $2 / 20$ & 0.152 \\
\hline $\operatorname{Hr}(0+\mathrm{S} / 1 / 2 / 3)$ & $8 / 27 / 7 / 0$ & $9 / 8 / 5 / 0$ & 0.085 \\
\hline Operation time (min) & 454 [208-913] & 517 [163-694] & 0.112 \\
\hline $\begin{array}{l}\text { Intraoperative } \\
\text { bleed }(\mathrm{ml})\end{array}$ & $390[10-1,655]$ & $590[92-1,940]$ & 0.026 \\
\hline $\mathrm{F} 0 / 1 / 2 / 3 / 4$ & $18 / 16 / 8 / 0 / 0$ & $0 / 0 / 0 / 12 / 10$ & $\mathrm{n} / \mathrm{a}$ \\
\hline $\begin{array}{l}\text { Histological diagnosis } \\
\text { (HCC/CCC/others) }\end{array}$ & $31 / 4 / 7$ & $20 / 2 / 0$ & 0.122 \\
\hline
\end{tabular}

the grades of cirrhosis (F0-2 vs. F3-4). In the F3-4 group, preoperative total bilirubin was significantly higher $(0.8 v s$. $0.6 \mathrm{mg} / \mathrm{dl} ; p=0.04)$, intraoperative bleeding was higher $(590$ vs. $390 \mathrm{ml} ; p=0.03)$, and $\Delta \mathrm{ICG}$ was higher $(4.1 \%$ vs. $0.51 \%$; $p=0.01$ ). Univariate logistic regression analysis was performed to determine the preoperative factors that predict F3 and F4, and it revealed larger value of total bilirubin, larger AST, and larger $\triangle \mathrm{ICG}$, thus showing significant associations with liver cirrhosis (F3-4) (Table IV). Additionally, the multivariate analysis revealed that a high $\Delta \mathrm{ICG}(\geq 3.4$, odds ratio $=4.9 ; 95 \% \mathrm{CI}=1.4-17.6 ; p=0.015)$, higher AST level (odds ratio $=1.1,95 \% \mathrm{CI}=1.0-1.2 ; p=0.026$ ), and an elevated total bilirubin level (odds ratio: 14.7; 95\% CI=1.1-202.6; $p=0.044)$ were statistically significant independent predictive factors for liver fibrosis (Table IV).

\section{Discussion}

To date, hepatectomy remains the mainstay of curative treatment for primary liver cancer $(2,23,24)$ and is one of the treatment options for metastatic liver cancer. Hepatectomy, the primary curative option for HCC and CCC and one of the most effective therapeutic options for metastatic liver cancer can remarkably improve overall survival. Improved overall survival also involves the safety of surgery $(3,4)$. It is thought that the improvement of perioperative management and surgical devices, accumulation of anatomical knowledge in liver surgery, and more accurate preoperative evaluation collectively contribute to improvements in surgical outcome. By combining various preoperative tests, the safety margin has become easier to understand than before; however, it is still true that excessive hepatectomy beyond the ability of the liver to regenerate leads to major morbidities including PHLF and mortality $(25,26)$, and making the decision of appropriate resection options for patients with cirrhotic livers is especially and extremely difficult (27). Although there have been many previous attempts to predict safety margins to avoid PHLF based on routine laboratory parameters, as previously mentioned, liver fibrosis with a single parameter has been difficult.

GSA is well-established and one of the most reliable liver function tests, in which the uptake region reflects living hepatocytes (28). Unlike the ICG test, GSA can be applicable for deployment among patients with various liver diseases with jaundice or intrahepatic vascular shunts. Nanashima et al. reported on the correlation between GSA-R15 and ICG15 and found that a more accurate evaluation of liver function and better prediction of patient outcome can be achieved by combining both (14). In their report, 12 of 140 patients had larger GSA-R15 than ICG-R15 results, including three of which had clear causes for such an outcome such as icteric liver or intrahepatic shunts, while, in other nine cases, the cause was not clear.

The current study first investigated the clinicopathological significance of a discrepancy in preoperatively measured GSA-R15 and ICG-R15 and the $\triangle$ ICG was extracted as one of the independent preoperative fibrosis predictors. The FIB4 index was not used for the multivariate analysis of fibrosis prediction by preoperative factors because it is already known to be a useful and established fibrosis marker. However, the FIB-4 index requires relatively complicated 
in vivo $34: 1187-1193(2020)$

Table IV. Univariate and multivariate logistic regression analysis: independent pre-operative predictive factors for liver fibrosis (F3-4).

\begin{tabular}{lcccccc}
\hline Characteristics & \multicolumn{3}{c}{ Univariate analysis } & & \multicolumn{2}{c}{ Multivariate analysis } \\
\cline { 2 - 4 } & Odds ratio & $(95 \% \mathrm{CI})$ & $p$-Value & & Odds ratio & $(95 \% \mathrm{CI})$ \\
\hline Total bilirubin $(\mathrm{mg} / \mathrm{dl})$ & 10.10 & $(1.355-75.352)$ & 0.024 & 14.739 & $(1.072-202.602)$ & 0.044 \\
AST $(\mathrm{U} / \mathrm{l})$ & 1.093 & $(1.029-1.161)$ & 0.004 & 1.087 & $(1.010-1.170)$ \\
PLT $\left(\times 10^{4} / \mu \mathrm{l}\right)$ & 0.929 & $(0.844-1.023)$ & 0.135 & & 0.026 \\
$\Delta \mathrm{ICG}(\geq 3.4)$ & 5.357 & $(1.749-16.409)$ & 0.003 & 4.910 & $(1.369-17.613)$ & 0.015 \\
\hline
\end{tabular}

calculations and is difficult to estimate immediately in clinical practice. On the other hand, $\triangle \mathrm{ICG}$ is a simple index able to confirm the difference between GSA-R15 and ICGR15 and may be a factor that can easily predict liver fibrosis.

This study is subjected to several limitations, including the limited sample size, its retrospective design, and the obscure scientific relationship between ICG-R15 and GSA-R15. Further studies are needed to gain more insight into this relationship. To address these issues, we are currently planning a prospective observational study. Preoperative knowledge in predicting hepatic fibrotic changes in patients undergoing hepatectomy will positively contribute to the prevention of PHLF and better decision-making prior to hepatectomy. The relationship between the divergence of ICG-R15 and GSAR15 and liver fibrosis may be due to the characteristics of ICG tests. In other words, as shown in Table II, a larger $\triangle \mathrm{ICG}$ was related to a lower BMI by univariate analysis. We believe that this relationship may be meaningful, although it was abrogated from the results of a multivariate analysis directed by the FIB4 index, which is known to have a strong relationship with fibrosis. Intravenously administrated ICG doses are determined based on body weight $(0.5 \mathrm{mg} / \mathrm{kg})$. On the other hand, although the liver volume is correlated with body weight, it is not directly proportional. Lighter people, i.e., those with lower BMIs, tend to have smaller volumes of ICG doses per liver volume. Considering that GSA-R15 reflects the function of the liver more, GSA-R15 naturally imparts larger values for those with poor liver function; however, among those of lighter weights, the use of ICG-R15 may be better. We believe this may be the reason for the dissociation of GSA-R15 and ICGR15 in patients with chronic cirrhosis.

In conclusion, preoperative $\triangle I C G$ was found to be a predictive factor for liver cirrhosis in this study. The results of this study suggest that the risk of clinically relevant and yet unrecognized liver cirrhosis can be predicted by measuring the gap between ICG-R15 and GSA-R15. Preoperative measurement of both ICG-R15 and GSA-R15 and the comparison of the two indices may be useful for identifying optimal therapeutic options for the patients considering hepatectomy.

\section{Conflicts of Interest}

The Authors have no conflicts of interest or financial ties to disclose regarding this study.

\section{Authors' Contributions}

TaH was involved with drafting of the manuscript and performed literature research and analysis. EU, TA and MM extracted data and performed a quality assessment. JW, KM, KK, TM, MY and YFuk were involved with the critical revision of the manuscript for the important intellectual content. NT, ST, TS and SH performed the figure and table drifting and the manuscript editing. ToH and YFuj supervised the study.

\section{References}

1 Makuuchi M, Kosuge T, Takayama T, Yamazaki S, Kakazu T, Miyagawa $\mathrm{S}$ and Kawasaki S: Surgery for small liver cancers. Semin Surg Oncol 9(4): 298-304, 1993. PMID: 8210909. DOI: 10.1002/ssu.2980090404

2 Farges O, Fuks D, Boleslawski E, Le Treut YP, Castaing D, Laurent A, Ducerf C, Rivoire M, Bachellier P, Chiche L, Nuzzo $\mathrm{G}$ and Regimbeau JM: Influence of surgical margins on outcome in patients with intrahepatic cholangiocarcinoma: A multicenter study by the afc-ihcc-2009 study group. Ann Surg 254(5): 824829; discussion 830, 2011. PMID: 22042474. DOI: 10.1097/SLA.0b013e318236c21d

3 Fan ST, Lo CM, Liu CL, Lam CM, Yuen WK, Yeung C and Wong J: Hepatectomy for hepatocellular carcinoma: Toward zero hospital deaths. Ann Surg 229(3): 322-330, 1999. PMID: 10077043. DOI: 10.1097/00000658-199903000-00004

4 Kanas GP, Taylor A, Primrose JN, Langeberg WJ, Kelsh MA, Mowat FS, Alexander DD, Choti MA and Poston G: Survival after liver resection in metastatic colorectal cancer: Review and meta-analysis of prognostic factors. Clin Epidemiol 4: 283-301, 2012. PMID: 23152705. DOI: 10.2147/clep.s34285

5 van den Broek MA, Olde Damink SW, Dejong CH, Lang H, Malago M, Jalan R and Saner FH: Liver failure after partial hepatic resection: Definition, pathophysiology, risk factors and treatment. Liver Int 28(6): 767-780, 2008. PMID: 18647141. DOI: $10.1111 / \mathrm{j} .1478-3231.2008 .01777 . x$

6 Jalan R, Sen S and Williams R: Prospects for extracorporeal liver support. Gut 53(6): 890-898, 2004. PMID: 15138219. DOI: 10.1136/gut.2003.024919 
7 Du ZG, Wei YG, Chen KF and Li B: An accurate predictor of liver failure and death after hepatectomy: A single institution's experience with 478 consecutive cases. World J Gastroenterol 20(1): 274-281, 2014. PMID: 24415882. DOI: $10.3748 / \mathrm{wjg}$. v20.i1.274

8 Makuuchi M, Kokudo N, Arii S, Futagawa S, Kaneko S, Kawasaki S, Matsuyama Y, Okazaki M, Okita K, Omata M, Saida Y, Takayama T and Yamaoka Y: Development of evidence-based clinical guidelines for the diagnosis and treatment of hepatocellular carcinoma in japan. Hepatol Res 38(1): 37-51, 2008. PMID: 18039202. DOI: 10.1111/j.1872-034X.2007.00216.x

9 Kawamura H, Kamiyama T, Nakagawa T, Nakanishi K, Yokoo H, Tahara M, Kamachi H, Toi H, Matsushita M and Todo S: Preoperative evaluation of hepatic functional reserve by converted icgr15 calculated from tc-gsa scintigraphy. J Gastroenterol Hepatol 23(8 Pt 1): 1235-1241, 2008. PMID: 18522682. DOI: $10.1111 / \mathrm{j} .1440-1746.2008 .05389 . \mathrm{x}$

10 Kira T, Tomiguchi S, Takahashi M, Yoshimatsu S, Sagara K and Kurano R: Correlation of $99 \mathrm{mtc}-\mathrm{gsa}$ hepatic scintigraphy with liver biopsies in patients with chronic active hepatitis type c. Radiat Med 17(2): 125-130, 1999. PMID: 10399780.

11 Sumiyoshi T, Okabayashi T, Negoro Y, Hata Y, Noda Y, Sui K, Iwata $J$ and Matsumoto M: (99m)tc-gsa spect/ct fusion imaging for hepatectomy candidates with extremely deteriorated icg value. Jpn J Radiol 36(9): 537-543, 2018. PMID: 29948545. DOI: $10.1007 / \mathrm{s} 11604-018-0753-0$

12 Torizuka K, Ha-Kawa SK, Ikekubo K, Suga Y, Tanaka Y, Hino $\mathrm{M}$, Ito $\mathrm{H}$, Yamamoto $\mathrm{K}$ and Yonekura $\mathrm{Y}$ : [Phase I clinical study on 99mtc-gsa, a new agent for functional imaging of the liver]. Kaku Igaku 28(11): 1321-1331, 1991.

13 Torizuka K, Ha-Kawa SK, Kudo M, Kitagawa S, Kubota Y, Tanaka Y, Hino M and Ikekubo K: [Phase II clinical study on 99mtc-gsa, a new agent for functional imaging of the liver]. Kaku Igaku 29(1): 85-95, 1992. PMID: 1770647.

14 Nanashima A, Yamaguchi H, Shibasaki S, Morino S, Ide N, Takeshita H, Sawai T, Nakagoe T, Nagayasu T and Ogawa Y: Relationship between indocyanine green test and technetium$99 \mathrm{~m}$ galactosyl serum albumin scintigraphy in patients scheduled for hepatectomy: Clinical evaluation and patient outcome. Hepatol Res 28(4): 184-190, 2004. PMID: 15040958. DOI: 10.1016/j.hepres.2003.11.010

15 Sumida Y, Yoneda M, Hyogo H, Itoh Y, Ono M, Fujii H, Eguchi Y, Suzuki Y, Aoki N, Kanemasa K, Fujita K, Chayama K, Saibara T, Kawada N, Fujimoto K, Kohgo Y, Yoshikawa T and Okanoue $\mathrm{T}$ : Validation of the fib4 index in a japanese nonalcoholic fatty liver disease population. BMC Gastroenterol 12: 2, 2012. PMID: 22221544. DOI: 10.1186/1471-230x-12-2

16 Vallet-Pichard A, Mallet V, Nalpas B, Verkarre V, Nalpas A, Dhalluin-Venier V, Fontaine H and Pol S: Fib-4: An inexpensive and accurate marker of fibrosis in hev infection. Comparison with liver biopsy and fibrotest. Hepatology 46(1): 32-36, 2007. PMID: 17567829. DOI: 10.1002/hep.21669

17 Kawamura H, Kamiyama T, Kurauchi N, Nakagawa T, Kamachi H, Yokoyama R, Kudo T, Shimokuni T, Matsushita M and Todo $\mathrm{S}$ : Preoperative evaluation of hepatic function reserve by converted icgr15 calculated from 99mtc-gsa scintigraphy. Jpn J Gastroenterol Surg 37(1): 14-20, 2004. PMID: 18522682. DOI: 10.1111/j.1440-1746.2008.05389.x
18 Ichida F, Tsuji T, Omata M, Ichida T, Inoue K, Kamimura T, Yamada G, Hino K, Yokosuka O and Suzuki H: New inuyama classification; new criteria for histological assessment of chronic hepatitis. Int Hepatol Commun 6(2): 112-119, 1996. DOI: 10.1016/S0928-4346(96)00325-8

19 Hanley JA and McNeil BJ: The meaning and use of the area under a receiver operating characteristic (roc) curve. Radiology 143(1): 29-36, 1982. PMID: 7063747. DOI: 10.1148/radiology. 143.1.7063747

20 DeLong ER, DeLong DM and Clarke-Pearson DL: Comparing the areas under two or more correlated receiver operating characteristic curves: A nonparametric approach. Biometrics 44(3): 837-845, 1988. PMID: 3203132.

21 Youden WJ: Index for rating diagnostic tests. Cancer 3(1): $32-$ 35, 1950. PMID: 15405679. DOI: 10.1002/1097-0142(1950)3: $1<32::$ aid-cncr2820030106>3.0.co;2-3

22 Sterling RK, Lissen E, Clumeck N, Sola R, Correa MC, Montaner J, M SS, Torriani FJ, Dieterich DT, Thomas DL, Messinger D and Nelson M: Development of a simple noninvasive index to predict significant fibrosis in patients with hiv/hcv coinfection. Hepatology 43(6): 1317-1325, 2006. PMID: 16729309. DOI: 10.1002/hep.21178

23 Wei AC, Tung-Ping Poon R, Fan ST and Wong J: Risk factors for perioperative morbidity and mortality after extended hepatectomy for hepatocellular carcinoma. Br J Surg 90(1): 3341, 2003. PMID: 12520572. DOI: 10.1002/bjs.4018

24 Schwartz M, Roayaie S and Konstadoulakis M: Strategies for the management of hepatocellular carcinoma. Nat Clin Pract Oncol 4(7): 424-432, 2007. PMID: 17597707. DOI: 10.1038/ ncponc 0844

25 Khan AS, Garcia-Aroz S, Ansari MA, Atiq SM, Senter-Zapata M, Fowler K, Doyle MB and Chapman WC: Assessment and optimization of liver volume before major hepatic resection: Current guidelines and a narrative review. Int J Surg 52: 74-81, 2018. PMID: 29425829. DOI: 10.1016/j.ijsu.2018.01.042

26 Deschenes M: Early allograft dysfunction: Causes, recognition, and management. Liver Transpl 19(Suppl 2): S6-8, 2013. PMID: 24038766. DOI: $10.1002 /$ lt.23746

27 Prodeau M, Drumez E, Duhamel A, Vibert E, Farges O, Lassailly G, Mabrut JY, Hardwigsen J, Regimbeau JM, Soubrane O, Adam R, Pruvot FR and Boleslawski E: An ordinal model to predict the risk of symptomatic liver failure in patients with cirrhosis undergoing hepatectomy. J Hepatol 71(5): 920-929, 2019. PMID: 31203152. DOI: 10.1016/j.jhep.2019.06.003

28 Nanashima A, Tobinaga S, Abo T, Nonaka T, Takeshita H, Hidaka S, Sawai T and Nagayasu T: Reducing the incidence of post-hepatectomy hepatic complications by preoperatively applying parameters predictive of liver function. J Hepatobiliary Pancreat Sci 17(6): 871-878, 2010. PMID: 20734210. DOI: 10.1007/s00534-010-0281-5
Received February 1, 2020

Revised February 13, 2020

Accepted February 17, 2020 